\title{
LA FORMACIÓN IDEOLÓGICA ESTÉTICO-LITERARIA \\ (Acerca de la reproducción y transformación del "efecto estético")
}

\author{
Por \\ FRANÇOISE PERUS \\ Instituto de Investigaciones \\ Sociales, UNAM.
}

"Sé lo que puede tener de un poco áspero el tratar los discursos no a partir de la dulce, muda e íntima conciencia que en ellos se expresa, sino de un oscuro conjunto de reglas anónimas. Lo que hay de desagradable en hacer aparecer los límites y las necesidades de una práctica, allí donde se tenía la costumbre de ver desplegarse, en una pura transparencia, los juegos del genio y de la libertad".

Michel Foucault, La arqueología del saber (353)

"¿Qué miedo es, pués, ese que le hace responder a Ud. en términos de conciencia cuando se le hable de una práctica, de sus condiciones, de sus reglas, de sus transformaciones históricas? ¿Qué miedo es, pues, ése que le hace a usted buscar, más allá de todos los límites, las rupturas, las sacudidas, las escanciones, el gran destino histórico-trascendental del Occidente?

A esta pregunta, estoy convencido de que la única respuesta que hay es política."

Michel Foucault, La arqueologia del saber (353) 


\section{LA FORMACION ESTETICO-LITERARIA: PROBLEMAS DE DEFINICIÓN}

Definiremos a la formación ideológica estético-literaria como el lugar del proceso de producción y reproducción de las ideologías estéticas que rigen, conjuntamente, la conformación del ámbito de la literatura y "lo literario", y las prácticas de la lectura y la escritura. Este proceso se inscribe a su vez en el marco del aparato ideológico constituido por el conjunto de instituciones de carácter escolar, universitario y para-universitario que domina dicha formación y asegura su reproducción.

Formulado en estos términos, el planteamiento apunta pues al esclarecimiento del funcionamiento concreto de la formación ideológica estético-literaria, y al de los mecanismos en los que descansa la reproducción del llamado efecto estético. Apunta asímismo al examen de las condiciones de su posible y necesaria transformación.

Para el análisis de los problemas planteados - que por ahora no pretendemos llevar a cabo más que en términos generales - conviene partir del estudio de las ideologías de carácter idealista predominantes en el seno de la formación ideológica en cuestión, para mostrar la función que objetivamente cumplen tales ideologías con respecto a la práctica de la lectura y la escritura y al establecimiento de las fronteras entre "lo literario" y lo "no literario", y sus efectos especificos en cuanto a la reproducción de determinadas formas de la conciencia social.

El estudio que proponemos conlleva entonces la adopción de una perspectiva materialista que, junto con devolver a las posiciones idealistas dominantes su justa dimensión y perspectiva histórica, debería llevar a la transformación de los planteamientos impuestos por aquella filosofía, a la vez que el bosquejo de una política cultural concreta en este campo particular; política concreta sin la cual la transformación en cuestión corre el riesgo de permanencer en el plano de los puros enunciados.

Lo formulado hasta aquí muestra desde ya que la formación ideológica estético-literaria es, como cualquier otra, una formación esencialmente contradictoria, en la que debaten posiciones idealistas y materialistas, y en la que, por razones que veremos más adelante, predominan las primeras. Predominio que implica antes que nada que las posiciones materialistas tienen necesariamente que definirse frente a una problemática que no es propiamente la suya $y$, por consiguiente, que sus posibilidades concretas de desarrollo radican no tanto en sus esfuerzos por contestar con el materialismo histórico y dialéctico a las preguntas formuladas por el idealismo, cuanto en su capacidad (no abstracta, sino histórica y socialmente dada) para reformular y transformar dichas preguntas.

De esta confrontación se desprende asímismo que en las distintas ideologías encontradas que configuran la formación estético-literaria, las 
posiciones idealistas y materialistas no se dan en estado puro, sino que en unas y otras tales posiciones se encuentran contradictoriamente imbricadas dentro de una relación desigual de dominación/subordinación, la cual se define fundamentalmente por el modo peculiar en que cada una de ellas asume y "resuelve" las contradicciones inherentes a la formación ideológica en su conjunto. Contradicciones éstas que giran en última instancia en torno a una oposición entre esencia y existencia, que en este campo particular ha asumido - al menos desde el advenimiento de la sociedad capitalista - la forma de una discusión en torno a la fundamentación del "valor estético", de las obras literarias y esto aún cuando cierto objetivismo positivista latente en algunas corrientes derivadas del estructuralismo linguístico, conjugadas - o no - con una sociología empirista de la lectura, puedan dar la impresión de que de un tiempo a esta parte los problemas del "valor" estético se han ido desplazando hacia los de la fundamentación "científica" de la "signficación". Sobre ello volveremos más adelante.

\section{LAS IDEOLOGIAS ESTETICAS DOMINANTES}

La literatura, o más bien lo que empíricamente consideramos como tal, no es como lo supone y a menudo lo afirma la filosofía idealista, una esencia siempre idéntica a sí misma, sino un campo de fronteras $y$ contenidos fluctuantes que se constituye y reproduce histórica y socialmente.

Pero este campo tampoco se constituye de manera lineal en el sentido de que, separándose paulatinamente de la magia, los mitos o la religión, y posteriormente de otras formas de discursos como el filosófico o el político, la literatura se fuera acercando cada vez más a "su esencia", entendida ésta como una esfera totalmente autónoma, cuyo desarrollo -o más bién variaciones - no obedecieran más que a sus propias leyes internas.

Ciertamente, el desarrollo material de la sociedad se acompaña necesariamente de una creciente división y especialización del trabajo tanto material como intelectual, que redefinen las formas de aprehensión y representación de la realidad y las distintas esferas de aplicación del saber. Pero la literatura, que no es propiamente un saber sino una práctica específica en la ideología situada en el nivel de lo "vivido", "sentido" y "percibido", no participa de la misma manera que las distintas disciplinas científicas de la creciente división social del trabajo intelectual: por cuanto aprehende la realidad en el nivel de los efectos objetivos y subjetivos de las estructuras y los procesos sociales sobre sus agentes, la literatura participa 
necesariamente no sólo del conjunto de formas culturales (imágenes, representaciones, símbolos) a través de los cuales tales efectos son vividos y percibidos, sino también de las contradicciones que, cimentándose en dichas formas culturales, definen a la lucha ideológica en su conjunto. Esta es, en efecto, la que en cada período determina las formas y los contenidos concretos de la conciencia social, y confiere sentido a los materiales culturales que reelabora, jerarquiza y desarrolla. Pero es además la que define - de modo siempre contradictorio - los ámbitos y niveles de la realidad susceptibles de ser aprehendidos y representados por la literatura, la función social asignada a ésta y el funcionamiento concreto del hecho literario. Y por ello, precisamente, por el sesgo de las ideologías estéticoliterarias y el "aparato" que las sostiene.

Las corrientes idealistas actualmente dominantes en el seno de la formación estético-literaria se articulan fundamentalmente en torno a dos concepciones básicas, complementarias entre sí, aún cuando - como veremos más adelante - una y otra no funcionen exactamente en el mismo nivel.

1) La literatura como expresión de la subjetividad individual del autor, concepción esencialmente basada en una doble separación: entre lo objetivo y subjetivo de una parte; entre lo individual y lo social de otra.

De acuerdo con ello:

a) Las representaciones literarias no guardan relación con la realidad histórico-objetiva, esto es con las estructuras sociales y los procesos históricos, ni por consiguiente con los efectos de ambos en la constitución de las formas de la conciencia social;

b) Por lo mismo, la subjetividad individual aparece desgajada del contexto histórico-social en cuyo marco se constituye como tal. El sujeto de la creación literaria tiene por tanto su principio en sí mismo, se agota en su creación y ésta con la sicología (o eventualmente el "inconsciente") del "sujeto creador".

Esta concepción no puede, por ello, más que desembocar en un tipo de crítica de carácter especular que, en el límite consiste en explicar la obra por la vida del autor, y ésta por aquella.

En cuanto al "valor estético" propio de la obra, de acuerdo con estos mismos supuestos, radicaría en la peculiar "sensibilidad" del artista unida a la "originalidad" de su creación.

Sin embargo, esta misma concepción de cuño romántico - que nace y se desarrolla en consonancia con el individualismo propio de la era liberal, al cual prolonga hoy en día más allá de sus límites históricos objetivos - 
tiene, paradójicamente, su complemento en una práctica empiricista de la historiografía literaria, en la que las separaciones antes mencionadas (entre lo objetivo y subjetivo de una parte, y entre lo individual y lo social de otra) vuelven a fundirse en una suerte de "espíritu de época" que permea la "conciencia colectiva" de modo más o menos homogéneo, o en un "telón de fondo" sobre el que se destacan, por su "sensibilidad" y "genio" propios, unas cuantas individualidades singulares que recogen y sintetizan mejor que otras el "espíritu de la época" de que se trate. Con lo cual no hemos salido, ni de los espejismos, ni de la circularidad ideológica, ya que tanto la "época como su "espíritu" y la "sensibilidad" del artista - y por tanto su obra - han sido concebidas a priori como totalidades homogéneas, y que la relación postulada entre esas totalidades sigue siendo una relación de identidad. Por lo mismo, lo que inicialmente se planteaba como la necesidad de llegar a dar cuenta de la "continuidad" y las "rupturas" en el desarrollo histórico de la literatura (sucesión de "movimientos", "escuelas", autores y obras) se resuelve mediante una serie de oposiciones y semejanzas parciales, no jerarquizadas (unas veces temáticas, otras veces formales), y más o menos contingentes. En cuanto al papel motor en la evolución histórica de la literatura, se le atribuye más que nada a un imperativo de renovación interna, al que coadyuvan unas cuantas influencias internas o externas, cuya selección es asímismo más o menos arbitraria.

2) La literatura como "lenguaje", o el lenguaje como materia, medio y fin del quehacer literario:

En el caso de estas "teorías", originalmente derivadas del estructuralismo linguístico, el problema fundamental radica no en la afirmación incuestionable - de que toda literatura mantiene relaciones específicas con "el lenguaje", sino en la concepción misma del lenguaje que les subyace, concepción que descansa en fin de cuentas en una confusión de planos entre el pensamiento (apropiación y representación en la conciencia de una realidad exterior a ella) y la materialización de éste en la lengua. Lo cual, en el límite, permite no sólo proyectar el conjunto de reglas lógico-formales que organiza el sistema de la lengua sobre el pensamiento y reducir éste a aquéllas, sino además convertir a dicha proyección en "esencia" del discurso literario.

En efecto, si bien es cierto que lenguaje y pensamiento son dos aspectos indisolublemente unidos en un mismo proceso, y que por lo tanto no hay ni signos vacíos de contenido, ni pensamiento fuera de su materialización en un sistema de signos (en este caso verbales), ello sin embargo no autoriza a reducir el pensamiento al conjunto de operaciones lógicas implicadas en su formalización lingứística, aun cuando -como es 
generalmente el caso en la literatura y más concretamente en la poesía -el plano lingüístico formal llegue a adquirir especial relevancia. (Tanto más cuanto que, al no tratarse de un pensamiento causal-conceptual sino concreto-sensible $y$, por tanto, esencialmente articulado en torno a ejes metafóricos y metonímicos, la coherencia semántica del texto - que no necesariamente quiere decir univocidad - tiene a menudo que ser subrayada con procedimientos estrictamente formales).

Antes que a una asimilación de ambos planos - que la corriente logicista-formalista actualmente predominante en el campo de la semántica concibe como proyección de las operaciones lógicas que rigen la organización del "significante" sobre el "significado" (con la consiguiente evacuación de toda referencia a la historia concreta, a las circunstancias de la enunciación como a las condiciones de producción de los enunciados de que se trate, y por ende al "lugar" del sujeto con respecto a las contradicciones que lo determinan) -, la indisoluble unión de lenguaje y pensamiento en todo proceso discursivo exige pues plantear el problema de la articulación entre ambos planos. En otros términos, en el campo de la semántica, haría falta desarrollar los instrumentos conceptuales que permitan deslindar y pensar dialécticamente un doble conjunto de relaciones: de una parte, las que existen entre el desarrollo de las formas ideológico-culturales y el proceso histórico global, y de otra, las que se hallan implicadas en la materialización de dichas formas en la base lingüística, entendida ésta como el conjunto más o menos homogéneo de reglas fonológicas, morfológicas y sintácticas que permiten, a partir de un léxico dado, la formulación de los enunciados requeridos.

Del carácter esencialmente dialéctico de esta doble articulación del proceso discursivo con instancias que tienen cada una sus propias leyes de funcionamiento y desarrollo (con las contradicciones ideológicas que se generan en el proceso histórico global, y con la base lingüistica que les sirve de soporte) se desprende por otra parte que si bien la base lingüística (o sea el sistema de la lengua) es en cuanto tal, ajena a la lucha ideológica, los recursos lingǘístico-formales movilizados en el proceso discursivo, en cambio, no son indiferentes a la producción de determinados efectos de sentido (efectos ideológicos), y contribuyen por ende, y desde su nivel específico, a la reproducción/transformación de las formas de la conciencia social. Por lo mismo, con todo y su "trabajo sobre el significante", el "efecto estético" - que tampoco se reduce a dicho "trabajo" - tiene que ser considerado como una forma específica de intervención en la ideología y analizado como tal.

Huelga decir que, debido a las concepciones idealistas que siguen envolviendo a las llamadas "ciencias del lenguaje", ni la semántica ni la semiótica parecen por ahora ofrecer respuestas a este tipo de problemas. 
Por lo mismo, toda tentativa de "articulación" del materialismo histórico y dialéctico con aquellas disciplinas conlleva la necesidad de un riguroso examen crítico de los postulados en los que éstas descansan, a la vez que su reformulación.

En otros términos, y respecto a los pasos metodológicos a seguir en los estudios concretos, el análisis "textual" tal como lo conciben las disciplinas en cuestión no puede considerarse como el paso previo al establecimiento posterior de la relación entre "texto" y "contexto", ni tampoco como el simple "complemento" en el plano de "la forma" de la reconstitución del "contenido ideológico". Y ello, por la sencilla razón de que ni la relación entre "texto" y "contexto" puede pensarse en términos de exterioridad, ni la que existe necesariamente entre "forma" y "contenido" se plantea en términos de una correspondencia entre ambos planos, ya que de lo que finalmente se trata es de llegar a dar cuenta de los efectos ideológicos específicos que, bajo la modalidad "estética", produce el texto en el interior de un campo ideológico-cultural, cuyos márgenes no están definidos por "texto en sí" sino por las contradicciones de la formación histórico-social concreta en cuyo marco se produce y reproduce la "significación" de la obra de que se trate.

Sea de ello lo que fuere, los supuestos idealistas en los que descansan las teorias formalistas a las que nos venimos refiriendo son los mismos que, retomando y extrapolando la distinción saussureana entre lengua y habla, conducen a fundamentar - de manera más implícita que explícita - el valor estético de las obras literarias en la singular complejidad de sus estructuras formales. Estructuras formales abstractas, y como tales "universales", que por lo mismo son susceptibles de adquirir todas las significaciones que desde fuera se quiera proyectar sobre ellas.

En cuanto a la posibilidad de llegar a dar cuenta del proceso histórico concreto de la literatura - preocupación que está lejos de constituir el centro de las reflexiones de la corriente crítica en cuestión -, o bien queda postergada en espera de volverse estructura de estructuras en nombre de una prioridad de la "sincronía" sobre la "diacronía", o bien, trasladada al plano de la "lectura" y sus "pluralidades" - que no es sino otra manera de obviar las determinaciones concretas de las obras literarias -, desemboca en un relativismo subjetivista, paradojicamente asentado en la "objetividad" de las "estructuras significantes".

3) Funcionamiento de las ideologías estéticas dominantes: desigualdad y complementariedad de funciones.

Después de poner de manifiesto los supuestos en los cuales descansan las dos tendencias críticas fundamentales que venimos examinando, queda por 
examinar su funcionamiento concreto en el marco del aparato ideológico que las sostiene. Más no sin antes de recalcar que, en la práctica, ni una ni otra se reducen a tales supuestos básicos que, de absolutizarse, podrían llevar a descartarlas de entrada por totalmente falsas. En sus aplicaciones concretas, contienen desde luego innegables elementos de conocimiento, aunque sólo fuera porque tienen que vérselas con una práctica concreta que tiende a resistir las reducciones a las que se la quiere someter, porque, aún a pesar de sus distorsiones, los problemas que recogen son sin lugar a dudas problemas reales: el del "lugar" del sujeto de la "creación" literaria en el primer caso, el de la especificidad del discurso literario en el segundo. Además de que estas mismas corrientes tampoco son del todo impermeables a otras tendencias críticas que provienen de horizontes ideológicos y filosóficos distintos.

Rescatar lo que de válido puedan involucrar las corrientes idealistas en cuestión en sus prácticas concretas no es, sin embargo lo que por ahora me propongo. Quisiera más bien destacar otro aspecto del problema, cual el es de la complementariedad de estas dos líneas críticas, aparentemente tan opuestas y desvinculadas entre sí que tienden incluso a circular y reproducirse en ámbitos distintos del aparato ideológico.

En efecto, mientras la primera constituye la corriente dominante en la enseñanza de nivel medio, la segunda es la que tiende a prevalecer en los ámbitos más altos de la docencia y la investigación universitarias.

Ligada al perfeccionamiento del aprendizaje de la lengua escrita, la primera es la que provee al alumno - que no necesariamente está destinado a convertirse ni en escritor, ni en crítico especializado - de "modelos" para aprender a "expresarse con estilo". Con lo cual, el acento está puesto, de una parte en la subjetividad individual - fuente implícita de la expresión literaria - y de otra en la noción de estilo - entendida como "suplemento" o "adorno" en el plano de la concreción lingǘísticoformal. $\mathrm{Y}$ como por otro lado se sienta como una evidencia que la subjetividad tiene su origen en la experiencia individual del sujeto experiencia que por lo demás se confunde con la representación que éste pueda tener de ella - bajo la vaga noción de "contenido", quedan entonces confundidos varios planos: el de las estructuras sociales, con el de sus efectos objetivos y subjetivos sobre sus diferentes agentes y con el de las formas ideológicas y culturales en el marco de las cuales son vividos y percibidos dichos efectos. Correlativamente, ni estas formas, ni los modelos linguísticos y estilísticos puestos en juego en el trabajo propio de la escritura llegan jamás a ser considerados en sus dimensiones a la vez históricas y prácticas: generalmente sacados de la llamada literatura "universal" (esto es sacralizada, previa separación de todo contexto histórico concreto), los modelos en cuestión - que junto con ser modelos 
para "expresar-se" son modelos para sentir y pensar —están ahí desde siempre, y para siempre, en su hierática belleza.

Resulta pues claro que la práctica de la lectura que, con base en semejante concepción de la escritura ("transparencia" de la realidad con respecto a su representación, y "transparencia" del lenguaje con respecto a ambas), se va conformando y reproduciendo en este ámbito relativamente masivo de la enseñanza de la literatura, tiende más que nada a reforzar los mecanismos de reconocimiento, identificación y sujeción ideológicas. Y no podemos olvidar que es ahí donde se forma la gran masa del público lector, no sólo de $L a$ Literatura, sino también y sobre todo de sus subproductos.

Mientras tanto, en los niveles superiores de la enseñanza universitaria, mucho más selectivos y especializados, la literatura, cercenada de sus dimensiones vivenciales, tiende a convertirse en objeto de arduas manipulaciones, a las que una sofisticada terminología técnica presta visos de cientificidad. En efecto, no deja de resultar paradójico el que, tras amputar el signo lingüístico de su función referencial y postergar la prise en compte del significado, el análisis "textual", centrado en la descripción formal del "significante", pretenda reencontrar a la salida de sus inventarios lo que previamente se había encargado de evacuar: esto es, precisamente la significación.

Mientras no se defina el estatuto teórico del nivel de organización lingüístico-formal, toda tentativa de deducir la significación del texto del conjunto de operaciones lógicas que necesariamente lo articulan en cierto nivel - conjunto de operaciones que como tal no encierra más significación, precisamente, que su carácter lógico-formal - reduce de hecho el análisis literario a una manipulación técnica que convierte a la lectura en una suerte de ritual, el cual no es en fin de cuentas sino la forma más sofisticada de la sujeción ideológica. Fuera de su contribución a la fetichización de la obra literaria, esta corriente no hace por ahora más que mimar, en su ámbito particular, las exigencias de rigor científico que desde hace tiempso - y no precisamente bajo la forma de ideologías tecnocráticas - se han hecho presentes en el campo de las disciplinas humanas y sociales.

Ahora bien, la relación que existe entre las dos tendencias críticas fundamentales que venimos examinando, no se reduce, clesde luego, a una simple diferencia de especialización entre grados de enseñanza. Con la disparidad de sus enfoques y la divergencia de sus orientaciones con respecto a la estructura social, estas tendencias determinan, como se acaba de ver, prácticas distintas de la lectura, y por lo tanto efectos ideológicoestéticos asímismo distintos.

Sin embargo, más allá de aquella disparidad de funcionamiento y funciones, lo que por ahora interesa mostrar es que ambas tendencias 
críticas contribuyen juntas, y desde un mismo campo particular - el de la literatura -, a la reproducción de formas de conciencia que vuelven difícil el cuestionamiento de la desigualdad de las relaciones sociales existentes, a la vez que de los distintos lugares y papeles que éstas asignan a los agentes sociales.

En efecto, sea que se privilegie al sujeto hasta convertirlo en principio y fin de la "creación literaria", o bien que evacuando al sujeto se convierta al lenguaje formalizado en materia, medio y fin del discurso literario, en ambos casos, lo que en torno a la pareja singularidad/universalidad se produce, no es en fin de cuentas otra cosa que la ocultación del carácter histórico-concreto de las prácticas literarias. Carácter histórico-concreto del que el sujeto es precisamente el "lugar", y que sólo puede aprehenderse poniendo de manifiesto las relaciones específicas que mantiene la literatura con la instancia ideológica, en el preciso sentido que confiere a este término el materialismo histórico.

Por lo ideológico, no se entiende desde luego aquí sólo a los sistemas de ideas articulados en forma conceptual, como pueden ser p.e. las ideologías políticas o los sistemas filosóficos, sino al conjunto mucho más laxo de ideas, representaciones, imágenes, símbolos, en el marco de los cuales los hombres viven, perciben y representan las contradiccion-es propias de la formación histórico-social en la que les ha tocado vivir, y su inserción concreta en ella.

Este conjunto de ideas, representaciones, imágenes, símbolos históricamente dado puesto que recoge y plasma la experiencia histórica colectiva - tiene pues una existencia objetiva, y como tal es anterior a las conciencias individuales que en él se reconocen. Es asímismo más o menos contradictorio, o al menos susceptible de ser interpretado, elaborado y transformado en varios sentidos. Pero estos sentidos varios tampoco son arbitrarios: son función, en primera instancia de la posición asumida por el sujeto con respecto a las contradicciones que lo constituyen como tal, y en última instancia de los distintos proyectos históricos de clase presentes y enfrentados en la formación social concreta de que se trate.

III. EFECTOS ESPECIFICOS DE LAS IDEOLOGÍAS ESTETICAS DOMINANTES

El ocultamiento de las relaciones que mantiene necesariamente la literatura con la instancia ideológica tal como la acabamos de definir conlleva una serie de correlatos importantes, que no están por demás precisar.

1) En primer lugar, la distorsión de los principales problemas que respecto de la significación, el valor estético y su perennidad se derivan del carácter histórico y socialmente determinado de las prácticas literarias. 
En efecto, de este carácter concreto de las prácticas de la lectura y la escritura, se desprenden antes que nada la no-inmanencia del sentido y la no-universalidad del valor de las obras literarias. De hecho, el sentido de las representaciones que articula una obra literaria dada, no es ni unívoco, ni inmutable. Es decir, que no es necesariamente el mismo para todos en el interior de una misma formación social, y que no permanece idéntico a sí mismo a través de todos los tiempos. Y, si bien es cierto que el texto como tal organiza dichas representaciones de acuerdo a una lógica propia, ésta, sin embargo, no es puramente formal, sino que resulta de esta dialéctica particular que se establece necesariamente entre unos materiales ideológico-culturales (representaciones, símbolos, etc.) ya cargados de sentidos plurivalentes, y el sentido que, de acuerdo con un proyecto ideológico-estético dado, busca conferirles el texto al estatuirlos como su interior.

De modo que el famoso problema del "trabajo sobre el significante", en el que algunos quisieran ver la esencia del discurso literario, no es propiamente un trabajo sobre el significante sino más bien un trabajo al interior del signo: trabajo de disociación, reapropiación y transformación, en un sentido determinado, de los significados de los que viene indefectiblemente cargado el significante, y que provienen a la vez de la tradición cultural heredada y de las prácticas sociales en que se van formando y ello, por la sencilla razón de que, como ya lo dijimos antes, no hay signos vacios de contenido - o más bien significante sin significado -, como tampoco hay significado fuera de un contexto concreto. $\mathrm{Y}$ también por lo que, no hay que olvidarlo, sobre el lenguaje "literario" pesa la fatalidad - ial menos que ésa sea precisamente su suerte? - de no poder desprenderse del todo del lenguaje común en el que se plasma la experiencia histórica colectiva.

De ahí que el plano de la organización formal o sea independiente de la elaboración de determinados contenidos ideológicos, y que, aun a despecho de la ilusión que al respecto pueda alimentar el autor, este plano no sea tampoco la simple manifestación de su libre albedrío, ya que las mismas propiedades del "referente" - naturales, sociales o culturales - fijan determinados límites a las posibilidades de reapropiación/transformación de los significados de los que el significante es el soporte lingüístico. De ahí también que la tenaz ilusión de autonomía que instaura el texto - y más que ningún otro el texto de ficción - tenga su contrapartida obligada en un no menos pertinaz efecto de exterioridad (que no necesariamente quiere decir "verdad"), sin el cual no se explicaría la ciclópea labor de interpretación de críticos y aficionados, que no por casualidad en algo se parece a la maldición de las Danaides. 
El que este efecto de exterioridad sea menos perceptible que su contrario por cuanto tiende a fundirse con la subjetividad del lector, y el que las ideologías actualmente dominantes en el seno de la formación estéticoliteraria busquen opacarlo o anularlo, es otro asunto que, de todos modos, no basta para suprimirlo.

Sea de ello lo que fuere, de lo anterior se desprende que el postulado de la inmanencia del sentido - en cualquiera de sus vertientes, empirista o logicista-formalista - , y el de la universidad del valor estético supuestamente inherente a determinadas obras literarias - que no es sino la prolongación del anterior - descansan en espejismos que convierten a dicha universalidad en una universalidad abstracta: sea que se quiera ver en cada individuo la manifestación de una supuesta "esencia humana", siempre renovada en lo singular y siempre idéntica en lo abstracto; o bien que se haga de los principios generales de la lógica formal y sus aplicaciones la manifestación de unas "estructuras universales del pensamiento", siempre renovadas en lo singular y siempre idénticas en lo abstracto.

Ahora bien, la no-inmanencia del sentido y el valor estético tampoco autoriza una salida hacia un relativismo subjetivista, ya que la lectura y los efectos ideológico-estéticos que produce no son arbitrarios: dependen conjuntamente de las propiedades de la obra de que se trate y de las ideologías estético-literarias que, en la práctica de la lectura, sobredeterminan la producción del llamado "efecto estético".

Respecto de lo primero, tiene que resultar claro que contrariamente a la orientación de las indagaciones derivadas del estructuralismo lingüístico, la posibilidad de "lecturas plurales" que ofrece efectivamente la literatura no conduce a tratar de aislar una supuesta esencia polisémica del signo lingüístico "literario", cuyas "actualizaciones" — variables al infinitodependerían de cada lector y su circunstancia particular. Pero tampoco consiste el problema en explicar a partir de qué condiciones sociales o culturales unas mismas estructuras lógico-formales adquieren significaciones distintas. En uno y otro caso, se sigue postulando que lo que preside a la estructuración de toda obra literaria es un modelo rigurosamente formal - esto es abstracto ya - histórico- que descarta toda determinación concreta de la obra, y convierte así a la tradición literaria -desprovista entonces de toda lógica histórica- en la yuxtaposición o acumulación arbitraria de unos cuantos artefactos listos para ser consumidos, de acuerdo con el gusto del momento, o de cada quien...

Siendo la polisemia un problema semántico y no propiamente lingüístico, la relativa inestabilidad semántica de los textos literarios (que por lo demás no es privativo de ellos) tiene necesariamente que ubicarse en las relaciones específicas que mantiene la literatura con la dinámica 
esencialmente contradictoria de la instancia ideológica y cultural, la cual no sólo constituye el horizonte semántico obligado del texto, sino también la "materia" que éste se apropia y estatuye como su interior, asumiendo al mismo tiempo una determinada perspectiva con respecto a ella. $\mathrm{Y}$ es precisamente en esta relación donde se definen las propiedades gnoseológicas, ideológicas e incluso estilístico-formales de toda obra literaria.

Ahora bien, dado que dichas propiedades no son cualidades intrínsecas sino instancias definibles en una relación que, sea dicho de paso lleva necesariamente a invertir la prioridad teórica y metodológica del "texto" sobre el "contexto", resulta claro que la relativa inestabilidad semántica del primero proviene antes que nada de la naturaleza esencialmente dinámica y contradictoria del horizonte ideológico y cultural sobre el que se recorta. En otros términos, esta relativa inestabilidad semántica tiene que verse y analizarse como resultado de los efectos específicos de las contradicciones ideológicas presentes en el seno de la formación social en su conjunto y sus repercusiones en la formación estético-literaria. A ello se suma desde luego el hecho de que, como lo señalábamos antes, las prácticas discursivas que históricamente se han ido constituyendo como "literarias" se caracterizan antes que nada por situarse en el nivel de lo "vivido" de la ideología, esto es de los efectos más que nada subjetivos de estructuras invisibles. Por lo mismo el amplio margen de indeterminación con que aparecen generalmente estas vivencias tiende a "universalizarlas", dando pie al mismo tiempo para esas "interpretaciones" en donde se reproducen aquellos mecanismos de reconocimiento e identificación subjetiva, de los que la primera corriente crítica que hemos analizado no es sino una forma privilegiada.

Por otra parte, tampoco cabe duda de que la evocación de estas vivencias mediante la asociación de imágenes y símbolos que sacan su carácter polisémico de las cualidades sensibles del referente a la vez que de la red de connotaciones socio-culturales en que éste se halla inserto, contribuye a una configuración relativamente laxa e inestable del universo del texto, en el que los elementos articulados conservan cierta autonomía.

Sin embargo, una obra literaria no es una colección de imágenes y símbolos sueltos, sino que para que sea reconocida como tal y llegue efectivamente a formar parte de la tradición (institución) literaria existente, tiene que llegar a recoger, condensar y plasmar, en su aparente autonomía estética, un universo en el que puedan reconocerse y con el que puedan identificarse sectores sociales suficientemente amplios y duraderos. Es decir, que tiene que alcanzar una significación que rebase lo puramente singular $\mathrm{y}$ anecdótico, e incluso lo meramente conyuntural, para convertirse en soporte de una fuerza histórica capaz de "universalizarla" en el marco de un contexto histórico concreto, o sea de convertirla en expresión del sentir histórico colectivo. Lo cual desde luego es una cosa 
totalmente distinta de la que consiste, para el escritor, en instalarse de entrada en una universalidad abstracta.

A la luz de estos planteamientos, incluso la perennidad de las obras literarias -o si se quiere su pervivencia más allá de sus condiciones históricas de producción-(hecho que hoy por hoy constituye uno de los caballos de batalla de la estética idealista en contra de las explicaciones de tipo histórico social) - deja de ser un problema metafísico. Una vez "institucionalizada" por obra de los factores histórico-concretos antes mencionados, toda obra literaria se convierta de hecho en uno de los elementos de la tradición cultural heredada, la cual, como se sabe, no es una colección de objetos listos para ser consumidos, sino la materialización de las distintas prácticas histórico-colectivas, como tal sujeta a una permanente reelaboración y reapropiación a partir de las nuevas perspectivas abiertas por el proceso histórico global, y -tratándose de la literatura a partir también de las consiguientes transformaciones de la formación estético-literaria y las ideologías que la configuran.

2) Además de las distorsiones antes mencionadas, de la ocultación del carácter histórico-concreto de las prácticas literarias, se desprende también, como primer corolario, la imposibilidad de llegar a reconstituir el proceso histórico real de la literatura a partir de las leyes generales que rigen la producción y reproducción de las prácticas de la lectura y la escritura, y el establecimiento de las fronteras entre lo "literario" y lo "no literario". El desconocimiento del funcionamiento de dichas leyes no sólo convierte este proceso en un proceso arbitrario, sino que deja libre campo a la actividad normativa de las estéticas idealistas. Actividad normativa cuya función esencial consiste en reproducir indefinidamente un valor abstracto, que si bien tiene que ver con la generalización de las relaciones capitalistas de producción que convierten a la obra literaria en mercancía, no deja de guardar estrecha relación con la reproducción de determinadas formas de conciencia social: en particular, en el nivel de la enseñanza masiva, la atomización de la conciencia histórico-colectiva, bajo la forma de una sujeción individual a condiciones de vida abstractas y por consiguiente no modificables; $y$ en el plano más selectivo, el desarrollo de una concepción tecnocrática de la "ciencia pura", desprovista de fines prácticos, que de paso se encarga también de neutralizar a su propio objeto de estudio.

No es por ahora mi propósito analizar los efectos concretos de dichas ideologías sobre la reconstitución (o no reconstitución) del proceso de la literatura latinoamericana y sus tergiversaciones - cosa que he emprendido por otra parte-, sino que quisiera subrayar que, en ausencia de una reconstrucción objetiva de tal proceso, resulta bastante difícil, para escritores (y críticos) imaginar las nuevas funciones y orientaciones posibles 
de sus prácticas, y más aún entender dicha actividad como un quehacer colectivo.

Con lo cual, llegamos al segundo corolario importante del soslayo de las determinaciones conćretas de las prácticas literarias por parte de las corrientes idealistas dominantes. En efecto, el predominio de dichas concepciones en el seno de la formación ideológica estético-literaria constituye sin lugar a dudas un poderoso freno para que los mismos escritores pudieran llegar a concebir su propio quehacer como una forma específica de la práctica social. No es por tanto de extrañar que a menudo su "vocación" se les aparezca como una actividad esenciamente solitaria (exorcización de demonios personales), desvinculada de la realidad social en su conjunto, e incluso de la tradición cultural y literaria de la que son los herederos, la cual tienden a considerar como un repertorio de formas y técnicas antes que como un proceso dinámico y contradictorio, con posibilidades de desarrollo en múltiples direcciones.

El oscurecimiento sistemático de tales perspectivas para la conciencia de un sinnúmero de escritores "profesionalizados"-en el sentido de que han llegado a concebir a la literatura como una esfera totalmente autónoma y dotada de sustantividad propia- no puede en efecto más que coadyuvar para que el quehacer literario se encierre en el solipsismo y para que la escritura, convertida en tema de sí misma, vaya reproduciéndose en los márgenes cada vez más estrechos de un círculo de iniciados. Sin percatarse de que el desarrollo actual de la literatura latinoamericana —en la práctica muy por encima de las ideologías reduccionistas al uso- no pasa necesariamente por ellos, estos escritores compensan su aislamiento real con la (sospechosa) convicción de estar salvaguardando la pureza del arte de toda contaminación ideológica e instrumentalización política, sin advertir tampoco, desde su altiva soledad, que la mejor manera de someterse a las leyes del determinismo consiste precisamente en querer ignorarlas.

En fin, y en relación con lo anterior, la ocultación de las relaciones que mantiene la literatura con la instancia ideológica, implica la imposibilidad de pensar el papel activo y especifico que desempeña la literatura en la reproducción/transformación de las formas de la conciencia social, bajo la modalidad del llamado "efecto estético".

Si no me han traicionado las formulaciones anteriores del problema, debería quedar claro que este papel no se desprende de las solas intenciones del artista, esto es, de la posición subjetivamente asumida por éste con respecto a las contradicciones que lo constituyen como tal y de las que éste es, por así decirlo, el centro, sin poder por ello, con su sola práctica de escritor, alcanzar las determinaciones últimas. 
En este sentido, las extensas discusiones acerca del "realismo" y el "compromiso del escritor", en las que por tanto tiempo se dejaron encerrar las izquierdas latinoamericanas - y no sólo ellas-, representan sin lugar a dudas una prolongación, en el campo del marxismo, de la primera corriente crítica antes analizada que quiere ver en la obra literaria a la vez la expresión de la subjetividad del autor y un reflejo (mecánico) de la "época" que le tocó vivir. El reemplazo del "espíritu de la época" por la "realidad objetiva", y de la subjetividad del autor por su ideología (política) de clase no basta para convertir en un análisis materialista a aquel tipo de planteamiento, cuyos reclamos descansan en un desconocimiento de la "materialidad" de la instancia ideológica y la especificidad de la literatura. $\mathrm{El}$ indudable voluntarismo que entraña dichas posiciones, más la consiguiente conversión de los críticos en censores de la pureza ideológica de los escritores en la que no pueden más que desembocar, han tenido una serie de consecuencias políticas nefastas que no es del caso analizar aquí, ni en sus causas ni en sus efectos. Sin embargo, tal vez no esté por demás recalcar que tales planteamientos y todas las falsas disyuntivas y malentendidos que suscitaron no tienen su origen tanto en la filosofía materialista, cuanto en el desconocimiento de ella, o más exactamente en la importación en el campo de ésta de problemáticas que no eran propiamente suyas.

Sea de ello lo que fuere, en contraposición con los planteamientos antes mencionados, lo que aquí se ha intentado mostrar es que la contribución específica de la literatura en la reproducción/transformación de las formas de la conciencia social resulta por igual:

1) de su carácter de práctica específica en la ideología (práctica en la que el proyecto ideológico-estético del artista es sólo un elemento estructurardor, que entra en relación dialéctica con la materia elaborada, y que, por consiguiente, no agota la significación de la obra), y de las propiedades (no intrínsecas) gnoseológicas, ideológicas y estilístico-formales que de ello se derivan; $y$

2) de las caracteristicas concretas de la formación ideológica estéticoliteraria, y en particular de la naturaleza de las ideologías estéticas predominantes en ella que sobredeterminan la producción del efecto estético.

\section{POSIBILIDADES DE UNA TRANSFORMACIÓN DEL EFECTO ESTÉTICO:}

$\mathrm{Si}$, como pensamos, las obras literaria no "significan" por sí solas, ni en virtud de una "esencia" supuestamente encerrada en ellas que la crítica tuviera por misión "develar", y si la significación —esto es la producción 
del efecto ideológico-estético- se halla sobredeterminada por las ideologías estéticas que rigen la práctica de la lectura, además de interrogarnos, como aquí se ha intentado, acerca de la función que objetivamente cumplen las corrientes críticas al uso, tenemos también que evaluar el tipo de lectura que queremos producir.

$\mathrm{El}$ afán nuestro por deslindar posiciones materialistas en este terreno no obedece, desde luego, a un prurito de pureza científica. Aún cuando el rigor científico constituya la condición necesaria para ubicar las contradicciones en que se hallan envueltas las teorías idealistas y medir los efectos específicos que objetivamente cumplen en la reproducción de determinadas formas de conciencia social, las tentativas por devolver a la literatura sus dimensiones histórico-concretas tampoco están desprovistas de fines prácticos. Estos, sin embargo, de ningua manera pueden consistir en hacer tabla rasa con la producción literaria existente en nombre de valores ideológicos incólumes: antes que trasladar a otro terreno la función esencialmente normativa de la critica idealista, los esfuerzos por sentar el análisis literario sobre bases materialistas tienen que dar lugar a la posibilidad de una reapropiación crítica de la tradición literaria heredada. Apropiación crítica que, a partir de la objetivación de las leyes generales que históricamente rigen la conformación y evolución de dicha tradición y el funcionamiento concreto del hecho literario, debería llevar al cuestionamiento de las funciones que las estructuras y los procesos sociales han ido asignando a las prácticas literarias. Pero no sólo eso: esta misma reapropiación crítica tendría que permitir devolver a las vivencias y representaciones artísticamente elaboradas por la literatura sus determinaciones histórico-concretas, es decir mostrarlas como lo que realmente son: efectos objetivos y subjetivos de estructuras y procesos sociales concretos sobre sus agentes. En fin, tiene que llevar a analizar la relación forma/contenido como una dialéctica concreta, no sólo porque la "forma" siempre lo es de un "contenido" concreto, sino también porque es precisamente por esta relación concreta en donde se manifiestan los problemas de adecuación / no adecuación entre la realidad y su representación, que la escritura es susceptible (desde luego, no sin la intervención de una lectura determinada) de convertirse en un discurso problemático, con efectos distintos a los que pretenden asignarle las corrientes críticas idealistas al uso.

Mientras la reapropiación crítica de la tradición heredada representa la condición necesaria para llegar a imaginar las nuevas funciones que dentro de las actuales condiciones del desarrollo histórico de la lucha ideológica y política de clases podrían asumir las prácticas literarias, la evidenciación de la dialéctica concreta entre "contenido" y "forma" - en el preciso sentido que le hemos asignado- nos parece constituir la condición de posibilidad 
para la transformación del efecto ideológico-estético en un sentido más acorde con este mismo desarrollo histórico. En efecto, una lectura que restituya a las vivencias y representaciones estéticamente elaboradas sus determinaciones concretas, suprime de hecho las bases en las que descansa la reproducción del efecto especular de reconocimiento, identificación y sujeción individual del lector a universales abstractos, que toda "lectura del texto en si" contribuye a reforzar. Sin negar la existencia de tales efectos, esta otra lectura, asentada en bases materialistas, conduce de hecho a amputarlos de su dimensión metafísica y, al articularlos sobre el proceso histórico-colectivo, abre y amplía para el lector la posibilidad de analizar y cuestionar el "lugar" que, en cuanto sujeto de prácticas diferenciadas, le asignan las estructuras sociales vigentes, y la concepción que de sí mismo tiene como agente del proceso histórico.

Dicho de otra manera, para que la literatura pueda cumplir con su papel de agente transformador ( $\mathrm{y}$ no sólo reproductor) de las formas de la conciencia social, es menester convertir a la lectura en la de-construcción -y no re- construcción (paráfrasis) - de esta unidad, tan ficticia como necesaria, en la que toda obra literaria busca aprisionar al lector incauto. Unidad ficticia que sólo se vuelve comprensible a partir de las contradicciones que la constituyen como tal, y de la materialidad de los elementos ideológico-culturales en que se asienta la ilusión que produce.

Si como piensan algunos, la función de toda ideología consiste en la "interpelación del individuo en sujeto", se habrá entendido que, de lo que con la lectura que proponemos se trata, no es obviamente de la supresión del sujeto en cuanto tal (y menos aún de la ideología), sino de abrir paso a la transformación de aquel sujeto individual que, en lo jurídico-político y en lo ideológico, siguen reproduciendo las instituciones burguesas, en unos sujetos cualitativamente distintos, que se sientan parte y se sepan dueños de un mismo proceso histórico colectivo.

Queda sin embargo por puntualizar los mecanismos en los cuales descansa la reproducción de esta relación desigual entre posiciones idealistas y materialistas en el seno de la formación ideológica estéticoliteraria, a la vez que su razón de ser histórica.

Más allá del problema espitemológico de base, lo que a lo largo de la presente exposición hemos intentado recalcar, entre otras cosas, es que la fetichización de las obras literarias bajo la modalidad de la permanente reproducción de un valor estético abstracto - correlato de la conversión de la literatura en mercancía-, no se da en abstracto, como una pura emanación de la generalización de las relaciones capitalistas de producción y el intercambio mercantil, sino bajo formas concretas, que implican la intervención directa de la superestructura, y más especificamente de un aparato ideológico determinado. En otros términos, las tentativas por 
autonomizar el valor de cambio del producto literario de acuerdo con los requerimientos de la base económica, van acompañadas, simultáneamente, de un intenso trabajo sobre el valor de uso (ideológico) del producto; trabajo que junto con contribuir a la mistificación de este último, apunta al propio tiempo a la producción de efectos ideológicos y políticos concretos.

Ahora bien, aún cuando, como hemos visto, tales efectos distan mucho de ser homogéneos - y no podría ser de otra manera, siendo que la estructura social tampoco lo es, y en este sentido afirmar simplemente que contribuyen a la "reproducción de la ideología dominante" es decir bien poca cosa-, su unidad fundamental radica en que impiden pensar no tanto la historicidad del valor estético, cuanto la de las relaciones sociales imperantes y la de los lugares y las funciones concretas que éstas asignan en todos los órdenes de la vida a sus agentes. Y si cuestionar dichos lugares y funciones lleva necesariamente al conocimiento de su dialéctica profunda, y por consiguiente a replantear la significación y el alcance de nuestras prácticas - literarias o no -con respecto al devenir histórico colectivo no resulta demasiado difícil entender las razones del bloqueo al que se hallan sometidas las posiciones materialistas en el sino del aparato ideológico que domina la formación estético-literaria.

Este bloqueo descansa ante todo en la aséptica separación mantenida, en la mayoría de los centros de educación superior (en donde se forman también los maestros de enseñanza media), entre las ciencias sociales propiamente dichas y las llamadas ciencias "humanas".

En consecuencia, los intentos por sentar al análisis de las manifestaciones artísticas sobre bases materialistas han partido por lo general de la filosofía antes que de las ciencias sociales, evocándose más que nada el establecimiento de los fundamentos de una "estética marxista". Sólo que, contrariamente a los que hubiera sido de esperar de planteamientos que se reclamaban del materialismo histórico y dialéctico, la profusa reflexión teórica en este campo, no ha desembocado en la recuperación de las prácticas artísticas concretas, ni en la reconstitución del proceso de la literatura o las artes latinoamericanas.

Sin menospreciar la importancia de la reflexión epistemolígica en un terreno en el que, más que en ningún otro, ha florecido el idealismo, personalmente pienso, sin embargo, que esta paradójica ausencia de estudios concretos no es del todo casual. Y no sólo por lo que la reflexión en cuestión se da en el interior de la filosofía, sino porque al partir de la tradición especulativa para negarla, no ha logrado todavía romper completamente con ella: el mismo postulado de una "estética marxista" sigue siendo una tentativa de respuesta a una pregunta equivocada: antes que seguir interrogándose acerca de una presunta esencia del arte (implícita en formulaciones tales como "¿qué es el arte?") incluso por encima de las 
distintas prácticas (literaria, pictórica, musical, etc.) agrupadas bajo una categoria empírica tan ambigua como la de "arte", corresponde al materialismo histórico y dialéctico desarrollar los instrumentos teóricos y metodológicos que permitan legar a dar cuenta de la materialidad de las diferentes prácticas que histórica y socialmente se han ido constituyendo en "artísticas". Más que ir en busca de lo que por encima del tiempo y el espacio supuestamente las unifica, conviene inquirir sus especificidades e indagar su razón de ser histórica. En ello radica la posibilidad de sus transformaciones, a la vez que la condición de su libre desarrollo.

Por otro lado, mientras la reflexión sobre los fenómenos artísticos y literarios permanece enfrascada en discusiones teóricas, cuyos alcances resulta muy difícil medir mientras no se confronten con las prácticas y los procesos reales de los que se supone están llamados a dar cuenta, en el campo de las ciencias sociales han ocurrido otros fenómenos no menos extraños.

Esencialmente orientadas hacia al análisis de los niveles económico y político y hacia la formulación de alternativas concretas en uno y otro campo, hasta ahora las ciencias sociales han tendido a pasar por alto la importancia de los factores ideológicos y culturales, no sólo en sus tentativas por reconstituir el proceso histórico global, sino incluso en sus investigaciones acerca de las transformaciones de las mismas estructuras económicas y políticas, como si éstas caminaran solas, independientemente de las fuerzas sociales que constituyen sus soportes a la vez que los agentes concretos de su reproducción y transformación. Sin embargo, la reproducción y transformación de las estructuras sociales no son el simple resultado de una implacable lógica natural del capital, sino el efecto contradictorio de prácticas sociales concretas, en las que las concepciones ideológicas y culturales que las rigen tampoco dejan de tener su peso específico. Tan es así que es precisamente en ellas y en gran medida por ellas que los distintos agentes sociales son susceptibles de constituirse en una fuerza histórica capaz de formular alternativas concretas al estado de cosas existentes. Y si bien es cierto que la formulación de dicha alternativa pasa necesariamente por la racionalidad política del proceso, tampoco se reduce a ésta: lo mismo que !as relaciones sociales de producción y las relaciones de poder tienen sus efectos específicos en todos los órdenes de la vida (pública y privada), para ser viables las alternativas planteadas tienen obligadamente que recoger y analizar en sus relaciones específicas con lo político aunque sin reducirlo todo a ello, las distintas problemáticas abiertas por el desarrollo sumamente complejo de las contradicciones en el seno de la formación social en su conjunto. Fuera de ello, no hay fuerza social alguna capaz de convertir a su propio proyecto histórico en el interés general de la nación, y por lo tanto de lograr una acumulación de fuerza 
suficiente como para permitir una transformación irreversible de las relaciones sociales existentes.

Mientras las leyes económicas (acumulación capitalista, reproducción ampliada, etc.) se nos sigan apareciendo tan inexorables como la voluntad divina, y el estado se nos siga presentando como el ministro de aquel nuevo dios todopoderoso (encarnado en el imperialismo, la oligarquía o la burguesía dominante), las ciencias sociales, olvidadas de que tienen que ser ante todo "portadores de acción" ( $\mathrm{y}$ de acción concreta), podrán seguir reputadas ajenas a los grandes problemas del "Hombre", mientras, por otro lado, la literatura (entre otras manifestaciones culturales) también podría seguir reputada ajena a los grandes problemas sociales. 
